\title{
Caregiver's Knowledge and Attitude Regarding Care of Schizophrenia at Mathari Teaching and Referral Hospital, Kenya
}

\author{
Edna Anab ${ }^{1}$, Agatha Christine Onyango ${ }^{2}$, Catherine Mwenda ${ }^{3}$ \\ ${ }^{1}$ Department of Public Health, Maseno University, Kisumu, Kenya \\ ${ }^{2}$ Department of Nutrition and Health, Maseno University, Kisumu, Kenya \\ ${ }^{3}$ Department of Medical and Surgical Nursing, Mount Kenya University, Thika, Kenya
}

Email address:

ednanab@yahoo.com (E. Anab), acatieno@yahoo.com (A. C. Onyango), mutungacs@gmail.com (C. Mwenda)

\section{To cite this article:}

Edna Anab, Agatha Christine Onyango, Catherine Mwenda. Caregiver's Knowledge and Attitude Regarding Care of Schizophrenia at Mathari Teaching and Referral Hospital, Kenya. American Journal of Psychiatry and Neuroscience. Vol. 6, No. 1, 2018, pp. 15-27. doi: 10.11648/j.ajpn.20180601.13

Received: November 20, 2017; Accepted: December 8, 2017; Published: January 16, 2018

\begin{abstract}
Schizophrenia is a mental disorder which is a major public health concern since it affects the quality of life of the schizophrenic patient. The patient requires a caregiver to support them in the entire phase of the condition. Caregiver's knowledge facilitate recognition of mental illness and health-seeking behavior. The aim of the study was to assess the caregiver knowledge and attitude regarding care of Schizophrenia. The study was conducted at Mathari Teaching and Referral Hospital, Kenya where the respondents were the caregivers of the schizophrenic patients. The research design used was cross-sectional mixed method. A total of three hundred and three respondents participated in the study, the respondents were selected by utilizing systemic sampling technique. A list was generated as the sampling frame every $3^{\text {rd }}$ patient on the list was selected. All the caregivers of the patient had an equal chance of participating in the study. Data collection instruments used were an objectively structured questionnaire and key informant guide which were used to solicit both qualitative and quantitative data. Descriptive statistics mainly measure of central tendency was used. Pearson correlation coefficient and logistic regression were used to determine the magnitude of the correlation. Qualitative data were analyzed through content analysis, similar themes were grouped. The findings indicate majority of the respondents 191 (63\%) were female while 218 (72\%) of the respondents did not know the name of the condition the patient was diagnosed with. Knowledge on schizophrenia significantly depended on the age of the caregiver $(\operatorname{Pr}=0.001)$ and the length of time the caregiver had taken care of the patient and knowing the patient $(\operatorname{Pr}=0.001)$ (Pearson chi2). Further modelling of these variables using logistic regression showed that caregivers' who have spent a long period with the patient are 3 times more likely to have a more positive attitude and be more knowledgeable compared to those who have spent a lesser period with a schizophrenic patient. The variable period with the patient is the most meaningful variable compared to the other variables in the model. Increasing the level of knowledge regarding the condition makes the caregiver more effective in their role as the patient's support system. These findings are a good opportunity for the formulation of interventions based on the identified gaps resulting to caregiver's full involvement in the care and management of the patient.
\end{abstract}

Keywords: Attitude, Knowledge, Caregivers, Schizophrenia

\section{Introduction}

Schizophrenia is a mental disorder, which was first discovered in 1896 by Kraeplin who termed it "dementia praecox" [4]. It is characterized by abnormalities in perception or expression of reality. The leading cause of this condition is not fully established it is mainly attributed to genetic predispositions combined with other environmental exposure [15]. The condition renders the patient disoriented, they require a caregiver to talk care of them [12]. Pilot programs in a few countries have proven the ability to improve the care of people with severe mental illness through the strengthening of the caregivers' knowledge.

It can be challenging taking care of a family member or 
friend diagnosed with Schizophrenia. The caregiver tends to be confused or panic in case they do not understand why the person is acting in a strange way [18]. One may not know how to react and what to do during such psychotic episodes. Caregivers help people with Schizophrenia to have a better prognosis. They provide doctors with important medical history information which aids to develop an effective treatment strategy [7]. The caregivers can provide Schizophrenic patients with a strong support system.

The perception about the condition may affect the health seeking behavior and response to treatment [1]. The belief about mental illness caused by the supernatural power makes the relatives to take mentally ill patients to traditional healers. The caregivers may seek herbal treatment and rush back to hospital facility after it's already too late. Medical intervention is an essential component in the management. Proper knowledge about Schizophrenia promotes caregivers to seek clinical interventions. The misconception about the condition and management has resulted to the patient to suffer due to delayed diagnosis [2] [5] [9] [11] [13].

Attitude can affect interaction by predisposing caregivers to act in ways that indicate acceptance or rejection towards the Schizophrenic patient [3]. Acceptance makes the patient feel loved by the family and caregivers thus resulting in improved quality of life. Rejection makes the caregiver feel burden living with a mentally ill relative [6]. Rejecting a Schizophrenic patient may, in return, cause him or her to suffer a relapse. Studies on relatives' attitude towards Schizophrenic patients began in early 1959, conducted by Brown and colleagues on the impact of family response towards patients discharged from a mental institution. There was a high rate of relapse to those who returned to live with their families [10]. Caregivers who are more understanding, encouraging and have a compassionate attitude towards the patient help them to achieve healthier social functioning. Thus, this makes the caregiver able to adjust their reaction according to the patient's emotional state and needs, this acts as a buffer since it protects them from a risky reaction that could trigger a relapse.

Caregivers may have varied perception regarding the prognosis of the patient which is based on their mental health literacy. In past studies caregivers elaborated that one cannot recover once diagnosed with a mental disorder [13]. Most of the respondents were sure that the illness would be chronic or eventually deteriorate. Despite that, they were convinced that the course of the illness could be influenced by psychiatric treatment as well as by the patients themselves [8]. The assessment of the prognosis of the schizophrenic illness by most relatives appears quite realistic. There is a chance that the perception of the prognosis is influenced by one's knowledge.

Caregivers knowledge towards mental health has a significant effect on the prognosis of the patient [20]. This area of mental health literacy remains relatively neglected. In the case of low mental health literacy, caregivers tend not to seek mental health services appropriately and not take good care of the patient. The caregivers actually try various treatments before deciding on the most reliable treatment for the patient. Given the evidence from the previous studies, there is need to explore this area further, thus this study assessed the knowledge of caregivers regarding the cause and management of schizophrenia.

\subsection{Statement of the Problem}

Schizophrenia is the leading mental illness, one of the most feared and yet also one of the most misunderstood [18]. It is a major public health concern since it affects the quality of life of the schizophrenic patient. In Kenya approximately $20 \%$ of patients seeking outpatient care in public and private institutions do suffer from some form of mental illness [16]. The number of people living with Schizophrenia has progressively increased over the years, currently approximately 450,000 people are suffering from Schizophrenia in Kenya [1]. Little is known about how caregivers' acquire knowledge about Schizophrenia in Kenya [19] [17]. The illness render the Schizophrenic patient sometimes unstable they require the help of the caregiver to continue being oriented. Caregivers knowledge facilitate recognition of mental illness and health-seeking behavior. The coping strategies they develop are based on their knowledge about mental illness [17]. There is a limited study done in Kenya regarding the caregivers knowledge on Schizophrenia. Based on the background information, the investigator postulates that there is need to assess the knowledge of the caregivers of the Schizoprenic patients.

\subsection{Objectives of the Study}

\subsubsection{General Objective}

To assess the caregiver knowledge and attitude regarding care of Schizophrenia at Mathari Teaching and Referral Hospital.

\subsubsection{Specific Objectives}

1. To assess the knowledge of the caregivers regarding Schizophrenia causes and management.

2. To assess the attitude of the caregivers towards Schizophrenia cause and management.

3. To establish the relationship between the caregivers' factors; knowledge and attitude in regards to Schizophrenia cause and management

\subsection{Research Questions}

1. What knowledge do the caregivers have regarding Schizophrenia cause and management?

2. What is the attitude of the caregivers towards Schizophrenia cause and management?

3. What is the relationship between the caregivers' factors; knowledge and attitude in regards to Schizophrenia cause and management?

\subsection{Significance of the Study}

This study was carried out in Mathari Teaching and Referral Hospital since it's the main national referral mental institution 
in Kenya drawing patients from various parts of the country. In a practical framework, the study assessed knowledge and attitude of the caregivers about Schizophrenia. The outcomes may be used to enrich limited existing knowledge regarding the area of study. It may provide information to the beneficiaries such as the patients, caregivers, hospital management, public and the policy makers. Hence, contribute to the improvement of the prognosis of the patient and eliminate the stigma associated with Schizophrenia from the public.

The findings presented here may be used towards helping the caregivers to be advocates for the person with Schizophrenia. Increasing the level of knowledge regarding the condition makes the caregiver more effective in their role as the patient's support system. These findings are a good opportunity for the formulation of family interventions based on the identified gaps resulting to caregiver's full involvement in the care and management of the patient. Also, broaden patient's support system through sensitization and education of the public.

\subsection{Conceptual Framework}

The conceptual framework was guided by the Health Belief Model particularly on how it explains people's perception regarding health actions. The model was first developed in 1950 by Hochbaum (1958), and later modified to include the influence of health motivation. The model is comprised of three primary components, including individual perceptions, modifying factors and factors affecting the likelihood of initiating or engaging in action. In the present study, it focused on the caregiver's individual knowledge and attitude regarding Schizophrenia. The modifying factors included a variety of selected demographic, socio-psychological and structural factors.

\section{Methodology}

This study adopted a cross-sectional mixed method (quantitative and qualitative) study design. The study was carried out in Mathari Teaching and Referral Hospital psychiatry wards. The hospital is situated along Thika road opposite Muthaiga police station about five kilometers from Nairobi city centre. The average bed occupancy at Mathari hospital is 650 beds. The hospital has a capacity of 700 beds comprising of 34 amenities (private) beds, 316 beds in the civil side and 350 beds in the maximum- security side. The admitted patients suffering from various psychiatric disorders. These patients are usually admitted when they exhibit anxious behavior, which relatives at home or community members consider as being uncontrollable.

\subsection{Study Population}

The study population for this study was all the caregivers who had schizophrenic patients at Mathari Hospital, Kenya. Study participants had to fulfill the following inclusion criteria; caregiver of a schizophrenic patient admitted at Mathari
Hospital, an adult aged 18-60 years and caregivers who gave informed voluntary consent to participate in the study.

\subsection{Sample Size Determination and Sample Procedure}

Based on September- December 2014 quarterly report, the inpatient capacity at Mathari Teaching and Referral Hospital was 975 patients and the total number of Schizophrenic patients was 384 . The sample size was calculated using the Fisher et al., 1991 sample size calculation standard formula. A total of 303 caregivers were involved in the study. Systematic sampling technique was then used to draw the samples. A list of the patients was generated as the sampling frame and using a skip pattern, every nth patient on the list was selected, where $\mathrm{n}$ was the sampling interval, calculated by dividing the total number of respondents /sampling frame with the sample size. $\left(n=3^{\text {rd }}\right.$ i.e. $\left.975 / 303\right)$. This way, all the relatives of the patient had an equal chance of participating in the study. To ensure total representation of the entire population, the caregivers were drawn from all the seven wards in the hospital.

\subsection{Data Collection Instrument}

\subsubsection{Questionnaire}

This study used structured questionnaires which included both open-ended and closed-ended questions. This yielded information on the knowledge and attitude of the caregiver regarding the care of Schizophrenia. Interview scheduled questionnaires were also used to collect qualitative data. Interview scheduled questionnaires were also used to collect qualitative data.

\subsubsection{Key Informant Interview}

The key informant interview guide was used to collect qualitative data. This yielded information on the role of the caregivers of the Schizophrenic patients.

One section of the guide solicited general information and the other remaining section was based on the role of the caregivers.

\subsection{Data Collection Procedure}

\subsubsection{Questionnaire}

The questionnaires were researcher administered questionnaire, where the researcher asked the question directly to the respondent and in certain circumstances translated the questionnaire to the respondents. Assistance was sorted in from persons who could translate the questions in various native languages.

The tool helped collect data aimed at addressing the first two objectives. The questions focused on the knowledge and attitude of the caregivers, the core of the study. Information on knowledge was generated based on the causes, management and prognosis of Schizophrenia while linking knowledge to the social demographic characteristics of the respondent. Information on attitude was evaluated through attitudinal statements which was utilized to capture the attitude of respondents on schizophrenia. All the attitudinal statements had a range from a minimum (1 point) to maximum (5 points), indicating a wide range of 
variations for the respondents to choose.

The questionnaire was written in both English and Kiswahili languages to allow easy interpretation by the correspondents. The process of filing the questionnaire was conducted at the wards while the respondents were visiting the patients, each data collection session took about 30 minutes.

\subsubsection{Key Informant Interview}

Health workers working in the psychiatric ward of Mathari Teaching and Referral Hospital, directly taking care of the Schizophrenic patients were the target key informants. Nurses were purposively selected given that they spent nearly 24 hours each day with the patients. Systemic sampling was used to select the nurses who, after selection, were given self-administered questionnaires to fill. A list of the nurses working in the psychiatric ward was used to calculate the skip pattern and interval of picking the nurses to be interviewed.

The interval was calculated by dividing the total number of respondents/sampling frame with the sample size. Ultimately, nine nurses were interviewed. Each interview took approximately 20 minutes. The tool was in English and contained seven key questions. One section of the guide solicited general information and the other remaining section was based on the role of the caregivers. The key informant interview tool was generated to find out the involvement of the caregiver of Schizophrenia patients on the care and management of the condition.

\subsection{Validity and Reliability}

Validity was done using content validity whereby the tool was reviewed by consultant in the subject area. Reliability was checked by conducting pretest and re test.

\subsection{Pre-Testing}

The research instruments were pre-tested at Mathari Teaching and Referral Hospital to check on the validity and reliability of the instruments. This process checked whether all the questions asked were eloquent and had the same meaning to all respondents. The pre-testing sample used was $10 \%$, a standard used for pre- testing (Mugenda and Mugenda, 1999). The respondents on which the instrument is tested was not part of the selected sample. During the pre- testing the researcher assessed the clarity of the instrument and the ease of the use of the instrument. This process also tested the rate of response depending on the type of response. Following this exercise, some revisions on the tools were made.

A key deliverable from this process led to a focused training of research assistants on the objectives of the study and how to best approach data collection in order to reduce variability and possible distortion of information during questionnaire administration.

\subsection{Measurement of Variables}

\subsubsection{Dependent Variable}

The dependent variables for this study were knowledge of the caregivers on schizophrenia and their attitude towards the illness.

\subsubsection{Independent Variables}

The independent variables for this study were characterized as summarized below:

\section{i. Caregiver Demographic Characteristics}

These comprised of data and information on age, sex, educational level, occupation and marital status. Age was defined as years since birth; sex as male or female; occupation as the nature of income generation whether formal or informal, education level as highest knowledge level of education attained. The solicited data facilitated assessment of the characteristics of the caregivers as factors that influenced knowledge and attitude.

\section{ii. Length of Time the Patient Has Been Suffering from Schizophrenia}

This was defined in either months or years the patient had suffered from Schizophrenia. The assumption at the time before data collection was that duration of illness could possibly influence the caregivers' knowledge and attitude.

\section{iii. Recurrence/Relapse of the Condition}

The study also sought out historical instances of recurrence or relapse of the condition in patients enrolled in the study.

\subsection{Data Analysis}

Data were analyzed both quantitatively and qualitatively.

\subsubsection{Qualitative Data Analysis}

Qualitative data were analyzed using content analysis with a focus on themes. After transcription of data, a critical review process looking at categories and creating broad themes and concepts leading to the analysis of the data was carried out.

In summary, the raw data was subjected to the following processes:-

1. Transcribed data were reduced through the process of critical reading and subsequent categorization of materials based on the study objective.

2. The lean data were then organized according to the research objective and themes

3. Data was then interpreted. This involved making decisions and drawing conclusions related to the evaluation questions and objectives. During this process, the organized data was explored in-depth.

\subsubsection{Quantitative Data Analysis}

Data was cleaned and entered into SPSS 16.0, 2010 software. Quantitatively, measures of central tendency descriptively summarized the results. Further to this, to understand relationships between variables, inferential analysis using Chi-square for independence was employed to understand whether the dependent variable (knowledge and attitude) indeed depended on the independent variables (age, education level etc). To compound this, logistic regression was then carried out to determine the magnitude and linearity of correlation between the relatives' factors to predict the perception and attitude as the dependent variable. For all 
analyses, the significance level was set at $\mathrm{p} \leq 0.05$.

\subsection{Ethical Considerations}

For the University institutional level, the researcher obtained permission from the School of Graduate Studies, Maseno University. The researcher then sought permission from Maseno University School of Graduates. For Facility level, the researcher obtained permission from the Kenyatta National Hospital/ University of Nairobi- Ethical Research Commission (KNH/UoN- ERC) reference number KNH-ERC/A/485 and The Medical Superintend of Mathari Teaching and Referral Hospital gave institutional permission to conduct research. From the caregiver level, the researcher sought informed consent from the caregivers who were briefed on the research procedures and they assured confidentiality.

Before participation, participants were informed of no incentives for participation. The benefits as a result of participating in the study were also outlined to them. It was very clear that their participation was a key step in generating knowledge to further the research agenda and ultimately focus and improve on prognosis and management of Schizophrenia. No coercion of the respondents took place and they freely and voluntarily took part in the study.

In line with the principle of beneficence, caregivers who expressed that were tired of taking care of the patient were encouraged and referred to the nurses for psychotherapy. The researcher helped particular caregivers to plan how they could further their knowledge on the condition.

\section{Results}

\subsection{Socio-Demographic Characteristics of the Respondents}

A total of 303 patients from Mathari Teaching and Referral Hospital in Nairobi County were recruited into the study. The majority of the respondents were female 191 (63\%). Out of the 303 respondents interviewed, nearly half $47 \%$ of participants resided in Nairobi and Kiambu counties while two respondents came from Uganda. Majority of the respondents were between the ages $35-44$ years (36.3\% male and $63.7 \%$ female). The mean age of the caregivers was 35-44 years. More than half $51.5 \%$ were either married while majority have attained secondary school level $156(51.1 \%)$, as illustrated in Table 1 .

Table 1. Socio-demographic Characteristics of the Respondents.

\begin{tabular}{|c|c|c|c|}
\hline Characteristics & Male & Female & Total \\
\hline Residence & n (\%) & n (\%) & n (\%) \\
\hline Nairobi & $29(29.5 \%)$ & $57(31.1 \%)$ & $86(28.0 \%)$ \\
\hline Kiambu & $16(38.1 \%)$ & $42(23.0 \%)$ & $58(19.0 \%)$ \\
\hline Other Counties & $65(13.3 \%)$ & $88(48.1 \%)$ & $153(51.0 \%)$ \\
\hline Uganda & $2(1.0 \%)$ & $4(2.2 \%)$ & $6(2.0 \%)$ \\
\hline Total & $112(100 \%)$ & $191(100 \%)$ & $303(100 \%)$ \\
\hline Age & n (\%) & n (\%) & n (\%) \\
\hline $15-24$ & $23(20.5 \%)$ & $50(26.2 \%)$ & $73(24.2 \%)$ \\
\hline $25-34$ & $31(27.7 \%)$ & $49(25.7 \%)$ & $80(26.4 \%)$ \\
\hline $35-44$ & $40(35.7 \%)$ & $70(36.6 \%)$ & $110(36.3 \%)$ \\
\hline Above 45 & $18(16.1 \%)$ & $22(11.5 \%)$ & $40(13.1 \%)$ \\
\hline Total & $112(100 \%)$ & $191(100 \%)$ & $303(100 \%)$ \\
\hline Marital Status & n (\%) & n (\%) & n (\%) \\
\hline Single & $37(33.0 \%)$ & $61(32.0 \%)$ & $98(32.3 \%)$ \\
\hline Married & $50(44.6 \%)$ & $107(68.2 \%)$ & $157(51.5 \%)$ \\
\hline Widowed & $13(11.6 \%)$ & $8(4.2 \%)$ & $21(7.1 \%)$ \\
\hline Separated & $12(10.7 \%)$ & $15(7.9 \%)$ & $27(9.1 \%)$ \\
\hline Total & $112(100 \%)$ & $191(100 \%)$ & $303(100 \%)$ \\
\hline Religion & n (\%) & n (\%) & n (\%) \\
\hline Christian & $96(85.7 \%)$ & $173(90.6 \%)$ & $269(88.9 \%)$ \\
\hline Muslim & $7(6.3 \%)$ & $12(6.3 \%)$ & $19(6.1 \%)$ \\
\hline Other & $9(8.0 \%)$ & $6(3.1 \%)$ & $15(5.0 \%)$ \\
\hline Total & $112(100 \%)$ & $191(100 \%)$ & $303(100 \%)$ \\
\hline Education & $\mathrm{n}(\%)$ & n (\%) & n (\%) \\
\hline None & $5(4.5 \%)$ & $7(3.7 \%)$ & $12(4.0 \%)$ \\
\hline Primary & $9(8.0 \%)$ & $22(11.5 \%)$ & $31(10.1 \%)$ \\
\hline Secondary & $52(46.4 \%)$ & $104(54.5 \%)$ & $156(51.5 \%)$ \\
\hline Tertiary & $46(41.1 \%)$ & $58(30.3 \%)$ & $104(34.4 \%)$ \\
\hline Total & $112(100 \%)$ & $191(100 \%)$ & $303(100 \%)$ \\
\hline Occupation & n (\%) & n (\%) & n (\%) \\
\hline Informal business & $59(52.7 \%)$ & 94 (49.2\%) & $153(50.5 \%)$ \\
\hline Formal education & $32(28.6 \%)$ & $78(40.8 \%)$ & $110(36.4 \%)$ \\
\hline Not employed & $21(18.7 \%)$ & $19(10.0 \%)$ & $40(13.1 \%)$ \\
\hline Total & $112(100 \%)$ & $191(100 \%)$ & $303(100 \%)$ \\
\hline
\end{tabular}

Most of the respondents 117 (38.5\%), were people not closely related to the patient. They were the patients' uncles, aunties, cousins or friends. The length of time spent looking after a schizophrenic patient varied $199(65.7 \%)$ of the 
respondents in these study had spent more than 10 years looking after the patient.

\subsection{Knowledge of the Respondents on Causes and Management of Schizophrenia}

Out 303 respondents $219(72 \%)$ were not aware of the name of the condition the patient while more than half of the patients had suffered from schizophrenia for more than 3 years.
The majority of the respondents $286(94.5 \%)$ were aware of the status of the patient in terms of them experiencing other conditions and the exact conditions they had experienced. Similarly, $283(93.4 \%)$ of the caregivers were aware, whether or not their patients had been admitted or not and the length of time they had been admitted. Averagely for this and other key variables, $288(95 \%)$ of all respondents knew their patient very well as illustrated in Figure 1.

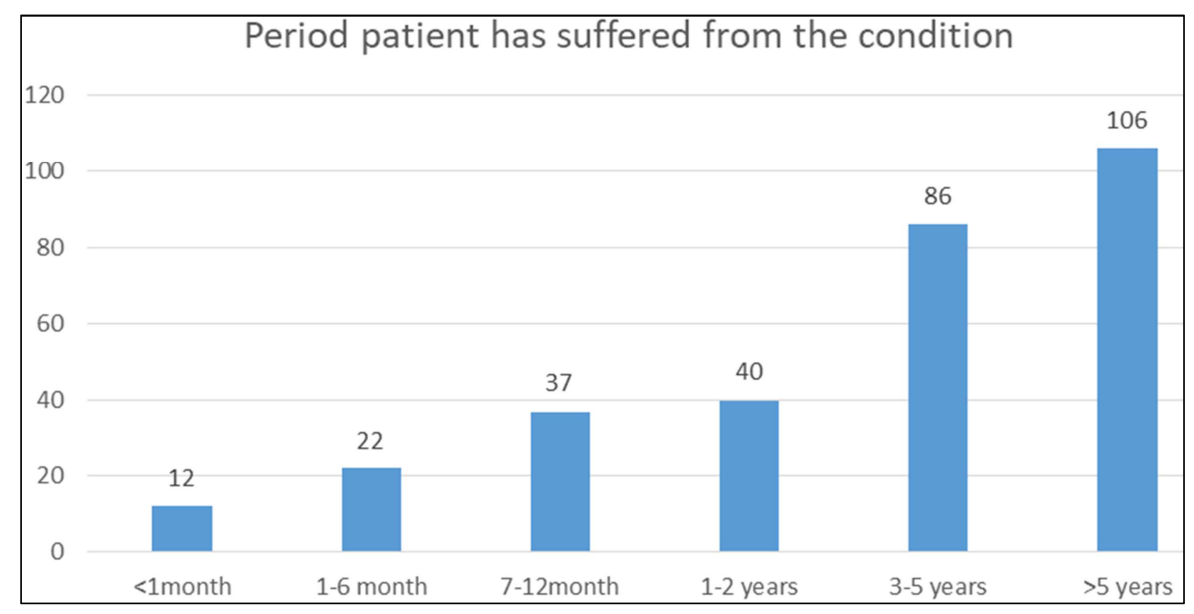

Figure 1. Period patient has suffered from the condition.

Further analysis using Pearson Chi square 2 showed a significant positive relationship between the length of time the caregiver had taken care of the patient and knowing the patient (Pearson chi2 $(2)=11.147 \mathrm{Pr}=0.001)$.

The knowledge of caregivers on causes, manifestation and management of schizophrenia is summarized in Table 2. In summary, $34(11.2 \%)$ did not know what the causes of schizophrenia were. Similarly, $28(9.3 \%)$ of the caregivers did not know the proper management of schizophrenia. The study found out that only $272(89.7 \%)$ of the caregivers were knowledgeable on causes and management of schizophrenia.

Table 2. Response of the Respondents on causes, manifestation and management of schizophrenia.

\begin{tabular}{|c|c|c|}
\hline Causes, Manifestation and Management & Frequency (n) & Percentage $(\%)$ \\
\hline Causes & $\mathrm{N}$ & $\%$ \\
\hline Stress and depression & 128 & 42.2 \\
\hline Drug and substance abuse & 74 & 24.6 \\
\hline Hereditary factors & 46 & 15.4 \\
\hline Cerebral malaria & 14 & 4.5 \\
\hline Head injury & 7 & 2.1 \\
\hline Total & 303 & 100 \\
\hline Manifestation of Schizophrenia & $\mathrm{N}$ & $\%$ \\
\hline Hallucinations & 127 & 30.0 \\
\hline Disorganized behaviour & 108 & 35.7 \\
\hline Loss of interest in one's with surroundind & 68 & 22.1 \\
\hline Do not know & 37 & 12.2 \\
\hline Knowledge of proper management & $\mathrm{N}$ & $\%$ \\
\hline Ensuring patient takes medicine & 111 & 36.5 \\
\hline Providing a good environment & 103 & 34.0 \\
\hline Being a caring and accepting caregiver & 61 & 20.2 \\
\hline Do not know & 28 & 9.3 \\
\hline Total & 303 & $100 \%$ \\
\hline
\end{tabular}

\subsection{Attitude of Respondents on Schizophrenia}

The mean of the attitude statements was 4.86 which suggest the respondents tend to agree with the statements. The respondents rated the statement given in Table 3. 
Table 3. Attitude of the respondents towards schizophrenia.

\begin{tabular}{|c|c|c|c|c|c|}
\hline Attitude Variable & Strongly disagree & Disagree & Do not know & Agree & Strongly agree \\
\hline & n (\%) & $\mathrm{n}(\%)$ & n (\%) & n (\%) & n (\%) \\
\hline Patients with Schizophrenia should not always be hospitalized & $59(19.4 \%)$ & $34(11.2 \%)$ & $28(9.2 \%)$ & $121(39.8 \%)$ & $61(20.4 \%)$ \\
\hline $\begin{array}{l}\text { The illness should not be hidden from the rest of my family and } \\
\text { friends }\end{array}$ & $71(23.5 \%)$ & $49(16.3 \%)$ & $19(6.2 \%)$ & $111(36.7 \%)$ & $52(17.3 \%)$ \\
\hline I really try to enjoy being with the patient at home & $44(14.6 \%)$ & $35(11.5 \%)$ & $22(7.3 \%)$ & $152(50 \%)$ & $51(16.7 \%)$ \\
\hline $\begin{array}{l}\text { I am comfortable talking to people about what happened to my } \\
\text { relative }\end{array}$ & $67(22.1 \%)$ & $54(17.9 \%)$ & $29(9.4 \%)$ & $89(29.5 \%)$ & $64(21.1 \%)$ \\
\hline
\end{tabular}

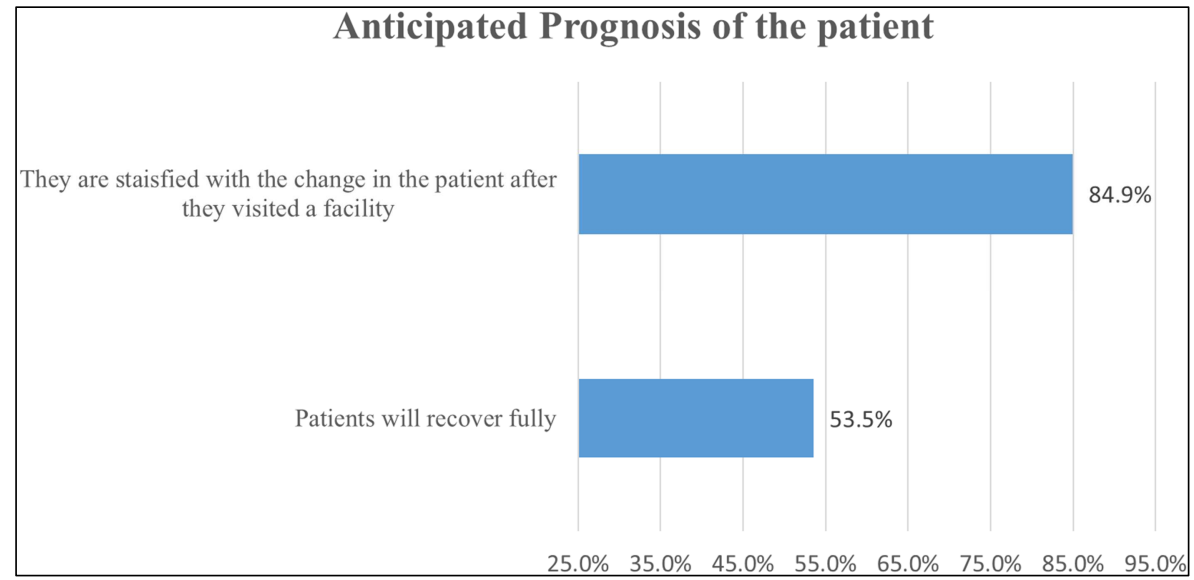

Figure 2. Anticipated prognosis of the patient.

Further to this, respondents were asked how they perceived the change in their patients before and after they received medication (the patients visited the facility). Most of the respondents $257(84.9 \%)$ were satisfied with the progress of the patient after admission. More than half 162 (53.5\%) of the respondents were confident that the patient will recover fully as shown in Figure 2.

\subsection{Factors Influencing Knowledge and Attitude of Caregivers on Care and Management of Schizophrenia}

To critically examine various factors and how they influence knowledge and attitude of the respondents on the care and management of schizophrenic patients, the Pearson chi-square test for independence was used. The dependent variables knowledge and attitude were categorically classified into two groups. For knowledge, one could be more knowledgeable or less knowledgeable depending on a range of factors. Similarly, the attitude was categorized as one having a positive attitude or a negative attitude depending on how they scored on the attitudinal statements.

\subsubsection{Factors Influencing Knowledge of Caregivers on Management of Schizophrenia}

A cross tabulation of knowledge and the age of the respondents as summarized in Table 4 show a strong (Positive) relationship $(\mathrm{Pr}=0.001)$ implying that older respondents have higher chances of being more knowledgeable compared to younger respondents are increasing as the age increases.

Table 4. Knowledge in Relation to Age of the Respondents.

\begin{tabular}{|c|c|c|c|c|c|}
\hline & \multicolumn{5}{|c|}{ Respondents Age Group } \\
\hline & $15-24$ & $25-34$ & $35-44$ & Above 45 years & P-Value \\
\hline More knowledgeable & $10 \%$ & $13.5 \%$ & $56.7 \%$ & $60.7 \%$ & $0.001 * *$ \\
\hline Less knowledgeable & $90 \%$ & $86.5 \%$ & $43.3 \%$ & $39.3 \%$ & \\
\hline
\end{tabular}

Key: $\mathrm{P}<0.05$.

A cross tabulation of knowledge and the education categories of the respondents as summarized in Table 5 show a weak relationship $(\operatorname{Pr}=0.752)$ implying that the two variables are independent of each other thus one does not necessarily depend on the other.

Table 5. Knowledge in Regard to Education Level.

\begin{tabular}{llll}
\hline & Respondents Education level & & \\
\cline { 2 - 4 } & Primary Education & Secondary Education & Tertiary Education \\
\hline More knowledgeable & $63 \%$ & $13.5 \%$ & $53.2 \%$ \\
Less knowledgeable & $37 \%$ & $86.5 \%$ & 0.752 \\
\hline
\end{tabular}

Key: $\mathrm{P}<0.05$. 
Similar to education, a cross tabulation of knowledge and occupation of the caregiver show a weak relationship $(\operatorname{Pr}=0.752)$ implying that the two variables are independent of each other thus one does not necessarily depend on the other.

Table 6. Knowledge in Regard to Employment Status of Respondents.

\begin{tabular}{lllll}
\hline & Employment status & & & \\
\cline { 2 - 5 } & Not employed & Informal business & Formal employment & P-Value \\
\hline More knowledgeable & $56 \%$ & $48 \%$ & $51 \%$ & 0.115 \\
Less knowledgeable & $44 \%$ & $52 \%$ & $49 \%$ & \\
\hline
\end{tabular}

Key: $\mathrm{P}<0.05$.

\section{i. Influence of Knowledge by the Period the Respondent Has Lived with the Patient}

The period with patient significantly related to the knowledge of the respondent on schizophrenia. A strong positive relationship $(\operatorname{Pr}=0.001)$ as indicated in Table 7 implied that the longer the period the respondent has spent with a patient, the more likely that they are more knowledgeable.

Table 7. Knowledge in Regard to the Length of Time Respondent has Lived with the Patient.

\begin{tabular}{llll}
\hline & Period Living with Patient & & \\
\cline { 2 - 4 } & Below 10 Years & Above 10 years & P-Value \\
\hline More knowledgeable & $11.2 \%$ & $90.1 \% \%$ & $\mathbf{0 . 0 0 1 * *}$ \\
Less knowledgeable & $88.8 \%$ & $9.9 \%$ & \\
\hline
\end{tabular}

Key: $\mathrm{P}<0.05$.

\section{ii. Relationship with the Patient}

Similar to education and employment status of the respondent, results showed that knowledge of the care giver did not depend on the relationship the caregiver had with the patient $(\mathrm{Pr}=0.305)$.

Table 8. Knowledge and Relationship to the Patient.

\begin{tabular}{lllll}
\hline & Relationship to Patient & & & P-Value \\
\cline { 2 - 5 } & Immediate Family & Parents and Siblings & Others & $\mathbf{0 . 3 0 5}$ \\
\hline More knowledgeable & $66 \%$ & $43 \%$ & $51.50 \%$ & $48.50 \%$ \\
Less knowledgeable & $34 \%$ & $57 \%$ & 5 & \\
\hline
\end{tabular}

Key: $\mathrm{P}<0.05$.

\subsubsection{Factors Influencing Attitudes of the Respondents on Management of Schizophrenia}

A cross tabulation of attitude and the socio demographic characteristics of the respondents as summarized in the Tables below (Table 9-12) show a strong (Positive) attitude ( $\mathrm{Pr}=$ 0.001) implying that period the respondent had lived with the patient, respondent age, relationship with the patient and respondent education greatly influence the respondent attitude.

The age of the respondent significantly related to the attitude of the respondent on schizophrenia. A strong positive relationship $(\operatorname{Pr}=0.001)$ as indicated in Table 9 .

Table 9. Attitude in Relation to Age of the Respondents.

\begin{tabular}{llllll}
\hline & \multicolumn{3}{l}{ Respondents age group } & & \\
\cline { 2 - 6 } & $\mathbf{1 5 - 2 4}$ & $\mathbf{2 5 - 3 4}$ & $\mathbf{3 5 - 4 4}$ & $\begin{array}{l}\text { Above } \\
\text { years }\end{array}$ & P-Value \\
\hline Positive attitude & $67 \%$ & $72 \%$ & $71 \%$ & $98 \%$ & $0.001^{* *}$ \\
Negative attitude & $33 \%$ & $28 \%$ & $29 \%$ & $2 \%$ & \\
\hline
\end{tabular}

Key: $\mathrm{P}<0.05$
The length of time respondent has lived with the patient significantly related to the attitude of the respondent on schizophrenia. A strong positive relationship $(\mathrm{Pr}=0.001)$ as indicated in Table 10 implied that the longer the period the respondent has spent with a patient, the more likely that they have a favorable attitude.

Table 10. Attitude in Regard to the Length of Time Respondent has Lived with the Patient.

\begin{tabular}{llll}
\hline & \multicolumn{3}{l}{ Period Living with Patient } \\
\cline { 2 - 4 } & Below 10 Years & Above 10 Years & P-Value \\
\hline Positive attitude & $54 \%$ & $96 \%$ & $\mathbf{0 . 0 0 1 *}$ \\
Negative attitude & $44 \%$ & $4 \%$ & \\
\hline
\end{tabular}

Key: $\mathrm{P}<0.05$.

The relationship of the respondent significantly related to the attitude of the respondent on schizophrenia. A strong positive relationship $(\mathrm{Pr}=0.001)$ as indicated in Table 11 implied that immediate family members are more likely to have a favorable attitude. 
Table 11. Attitude and Relationship to the Patient

\begin{tabular}{lllll}
\hline & Relationship to Patient & & & \\
\cline { 2 - 5 } & Immediate Family & Parents and Siblings & Others & P-Value \\
\hline Positive attitude & $92 \%$ & $84.8 \%$ & $76.9 \%$ & $\mathbf{0 . 0 0 1}$ \\
Negative attitude & $8 \%$ & $15.2 \%$ & $23.1 \%$ & \\
\hline
\end{tabular}

Key: $\mathrm{P}<0.05$.

The education level of the respondent significantly related to the attitude of the respondent on schizophrenia. A strong positive relationship $(\mathrm{Pr}=0.001)$ as indicated in Table 12 implied that the more educated one is the more they are able to accept a mental illness.

Table 12. Attitude in Regard to Education Level.

\begin{tabular}{lllll}
\hline & \multicolumn{2}{l}{ Respondents education level } & & \\
\cline { 2 - 5 } & Primary Education & Secondary Education & Tertiary Education & P-Value \\
\hline Positive attitude & $45 \%$ & $67 \%$ & $90 \%$ & $0.001^{*}$ \\
Negative attitude & $55 \%$ & $33 \%$ & $10 \%$ & \\
\hline
\end{tabular}

Key: $\mathrm{P}<0.05$.

\subsection{Relationship between the Caregivers' Factors Knowledge and Attitude}

The results below were modeled from logistic regression since both independent variables (period living with the patient, respondent's age, relationship to the patient and education) and the dependent variable (knowledge and attitude of the respondents) are binary variables. A key component of these results is the $\operatorname{Exp}(\mathrm{B})$ (the exponentiation of the $\mathrm{B}$ coefficient) which is an odds ratio. The Exp (B) column in Table 13 presents the extent to which raising the corresponding measure by one unit influences the odds ratio.

The Exp (B) value indicates that when the 'period with patient' factor variable is raised by one unit, the odds ratio is 3 times as large and therefore respondents who have spent a long period with the patient are 3 times more likely to have a more positive attitude and be more knowledgeable compared to those who have spent a lesser period with a schizophrenic patient. These results also show that the variable period with the patient is the most meaningful variable $(\mathrm{P}=.001)$ compared to the other variables in the model.

Table 13. Factors Influencing Knowledge and Attitude of Caregiver.

\begin{tabular}{|c|c|c|c|c|c|c|c|}
\hline \multicolumn{8}{|c|}{ Variables in the Equation } \\
\hline & & B & S. E. & Wald & Df & Sig. & $\operatorname{Exp}(B)$ \\
\hline \multirow[t]{5}{*}{ Step 1a } & Period with patient & 1.270 & .253 & 11.578 & 1 & .001 & 3.560 \\
\hline & Age & -.862 & .596 & 4.542 & 1 & .033 & .422 \\
\hline & Relationship to patient & -.351 & .247 & 2.020 & 1 & .155 & .704 \\
\hline & Education category & -.072 & .356 & .041 & 1 & .839 & .930 \\
\hline & Constant & -.073 & .215 & .113 & 1 & .736 & .930 \\
\hline
\end{tabular}

Key: Variable (s) entered on step 1: Period with patient, Age, Relationship to patient, Education category.

\subsection{Care and Management of Schizophrenia}

Results from the key informant generated information on the care and management of Schizophrenia, while also focusing on the involvement of the caregivers in the management of the condition.

\subsubsection{General Information about the Schizophrenia Patients}

More than half of the patients who had been admitted in wards were diagnosed with schizophrenia. Most of the admissions are involuntary admissions, whereby the patient is brought in by family or relatives. The nurses stated the services offered at the facility to the schizophrenic patients include: medication, sports, individual and family counseling.

\subsubsection{Support Therapy Offered to Schizophrenic Patients}

The support therapy includes biological, psychological and social therapies. The biological therapy is the antipsychotic drugs administered. Psychosocial therapy focuses on the patient's relationship with others. Medication and family support were seen to be the most support activities for recovery.

\subsubsection{Involvement of Caregivers in the Management of Patients}

Most of the nurses reported a high level of involvement by the caregivers of the newly diagnosed patients compared to the ones who had suffered from schizophrenia for a long time. Some of the caregivers of the patients who had incurred relapse had abandoned the patients at the hospital.

\subsubsection{Knowledge of Caregivers on the Cause, Management and Prognosis}

The caregivers are educated when the patient is admitted and during the subsequent visit on the management and prognosis of the patient by the health care workers. The nurses reported that the clients whose patient had suffered from 
schizophrenia for long are more knowledgeable on the condition. Most of the respondents said that they knew the illness from the patient's experience, some from the health workers and other through friends.

\subsubsection{Attitude of Caregivers}

Most the caregivers once the patient is newly diagnosed they are really eager to understand the condition. Caregivers who have patients who have suffered for a long time and tend not to improve have an unfavorable attitude.

\subsubsection{Challenges Experienced by Caregivers after Discharge of the Schizophrenic Patient}

The key informants all agreed that schizophrenia can be managed at home thou the major challenge is patients are not brought frequently for clinical consultation. The major problems that prevent some caregivers from bringing the patient for consultation clinics include finance, transport, refusal by patients and some forget return date. Other problems mentioned were having stock out of antipsychotic drugs at home and aggressive behavior of patients. The caregivers expressed both emotional burnout and financial constraints due to taking care of the patient. Most of the caregivers readmit the patient after they experience a relapse while some will report to the police due to the violent behavior. Most of the respondents expressed feelings of being alone, isolated and labeled due to having a mentally challenged.

\section{Discussion}

\subsection{Socio-demographic Characteristics}

Research on schizophrenia has shown caregivers can make a significant impact in the overall road to recovery of the patient. This study underscores the importance of caregivers and shows results on their knowledge, their attitudes and factors that shape these aspects. Based on the findings, education level, occupation and marital status of the respondent had a weak relation in regard to knowledge and attitude. On the other hand gender, age, relation to patient and how long the respondent had lived with the patient contributed greatly towards their knowledge and attitude.

This study shows that most of the respondents 191 (63\%), were female. A study conducted by McWilliams "Caregiver Psychoeducation for Schizophrenia: is gender important? concurs with the results finding that females are more caring compared to male since they visit their sick relatives frequently and based on knowledge regarding schizophrenia they understand the condition since they have been with their beloved ones through their acute stage. In this study female caregivers were more knowledgeable since they were able to recognize the symptoms, management and the care the patient needed to recover, while male caregivers more knowledgeable about the risk factors [22].

Age can act as a factor that contributes towards one's eager to understand the condition that their relative is suffering from. In the past studies, researchers mainly carried out research on which age group is more prone to suffer from Schizophrenia.
According to the Philosophy scholars, one becomes wiser the older they became [21]. Based on this statement if one was to compare the level of knowledge between age group 17-27 and 32-49 years the age group 32-49 years would be more acquitted with knowledge on Schizophrenia. This concurs with the study since the older respondents were more knowledgeable.

According to the Schizophrenia Foundation of Kenya two-day family education workshop which was held in Nairobi in March of 2002, they noted that most of the participants had attained secondary and university education. Based on family education workshop, the higher the level of one's education makes one thirstier for acquiring knowledge. An educated relative would want to know more on what their beloved one is suffering from and also what role they can play in helping their sick relative [1]. This contradicts with the findings of the study since in this study education of the caregiver has weak relation with the knowledge of the respondent.

The study shows 117 (38.5\%), were people not closely related to the patient. The caregivers were drawn from friends and the extended family. For this study, most caregivers were the patients' uncles, aunties, cousins or friends. The fact that most caregivers were not the patients immediate family shows the social cost of the disease to the family. Other key studies have shown that if a family member or someone close to a caregiver has schizophrenia, the caregivers struggle with difficult emotions, including fear, guilt, anger, frustration, and hopelessness [5] [6] [21]. The illness is often difficult for them to accept. This study gives findings from caregivers whom most of them $200(65.7 \%)$ have spent more than 10 years looking after the patient.

\subsection{Knowledge of the Caregivers of Schizophrenic Patients Regarding the Causes and Management}

It is important for caregivers to learn about schizophrenia and how to manage it. This allows them to make prompt decisions about how best to manage the illness, work toward recovery and handle any setbacks. This study made inquiries about the caregiver's knowledge in terms of cause and management of schizophrenia.

The term schizophrenia was new to them but the understanding of the nature of the illness from the caregivers' perspective was not restricted to knowing the name of the diagnosis but to general mental illness. The caregivers said that living with the patient taught them many things about the mental illness. A similar research was done in the Arabian community to find out what the relatives perceived was the cause of schizophrenia, less than a half $(25 \%)$ of the respondents believe the illness is caused by witchcraft. Thou this study was conducted in a larger study population it concurs with the findings of this study since $34(11.2 \%)$ did not know the cause of Schizophrenia. This misconception may cause them to consult traditional healers and marabous, lack of knowledge regarding the cause of schizophrenia can lead to delay in diagnosis and treatment and worsen the illness prognosis [11]. Family members of people suffering from 
schizophrenia should be equipped with adequate knowledge regarding the cause of the condition to enable their contribution to the management of their sick relatives' thereby reducing the stigma associated with schizophrenia.

The findings indicate that majority of the patients 192 (63.4\%) have been suffering from schizophrenia for more than three years, thus this may contribute to better understanding and knowledge of their caregivers since they have experienced the condition for a long duration. In a study conducted at Nigeria by Awaritefe et al on the effect of relapse on the relatives understanding on schizophrenia concurs with the findings of this study since it was found that the relatives who's loved ones had experienced the condition more than one year had a greater understanding of schizophrenia in terms of cause, management and prognosis [2]. The length of time the caregivers have spent, in terms of everyday management of the patient, plays a crucial role in the depth at what the caregiver will know. This study has shown a significant positive relationship between the length of time the caregiver had taken care of the patient and knowing the patient.

This study also showed that most 283 (93.4\%) of the caregivers were aware of the medical history and interaction with the health facility. The caregivers in this study knew about whether or not their patients had been admitted before in a medical facility and the length of time they had been admitted. The findings in this study are comparable to the findings in a study by [14] in the study which showed that $89.7 \%$ of the caregivers were knowledgeable on causes and management of schizophrenia. This and more studies have shown that a knowledgeable caregiver is an essential component in the management of the patient.

\subsection{Attitudes of the Caregivers towards Schizophrenia Cause and Management}

The importance of the right attitude of a caregiver towards schizophrenia and management of their patient cannot be over emphasized. A caregiver who portrays rejection attitude towards the patient is actual incompetent in their role as a caregiver. A study on attitudes of Americans towards schizophrenia shows a more positive attitude with $85 \%$ of the interviewed recognizing that this is an illness and that with continuous care the patient can live independent life. Other studies have shown results contrary to this depending on their socio-cultural background. A study Weissman (2003) showed that Schizophrenic patients and their families have difficulty adhering to medical interventions. As a result, the patients die averagely 25 years sooner than the general population. The findings from this study showed that with a knowledge caregiver, the attitude towards schizophrenia and its management is positive. With this positive attitude, the caregivers perceived a more positive and bearable prognosis. From this study, above three-quarters $(84.9 \%)$ of all caregivers interviewed were satisfied with the progress made by their patients each time they visited a medical facility and half of them $(53.5 \%)$ were convinced that their patient was on the path to full recovery.

\subsection{Factors That Influence the Knowledge and Attitude of the Caregivers}

As clearly highlighted in this study, there is a glaring gap in drivers of the knowledge and the attitudes of the caregivers. In Kenya, minimal studies have been conducted about how caregivers' acquired knowledge and attitude about Schizophrenia. Most importantly, what shapes their knowledge or the opportunities to be knowledgeable and their attitude has not been investigated before. The findings in this study highlight how certain socio-demographic indicators model the overall attitude and knowledge of a caregiver on schizophrenia and its management. The study found out how education level, their ages, their relationship to the patient and the relationship status of the caregiver of the caregiver affect the overall knowledge and attitude of the caregiver.

Education: The results showed a weak relationship between the education level of the caregiver and impact on their knowledge. This result shows that how educated the caregiver does not necessarily reflect their knowledge and attitude towards schizophrenia and its management. This implied that it takes more than the normal Kenyan education curriculum to transfer necessary mental illness knowledge to an individual. This pointed to a deliberate effort by a caregiver or other persons, whether knowledgeable or not, to learn and get involved in care and management of a schizophrenic patient. Some of these deliberate efforts have been shown by a study by Coursey (2001), where programs were designed in Beijing, China to carry out family education on schizophrenia to educate the masses. This program was very impactful and results showed an increased awareness of the patient's family including other relatives.

Age of the caregiver: this study showed a strong positive relationship between the caregiver's age and their knowledge on schizophrenia and its management. From the study, older caregivers were more knowledgeable compared to younger caregivers. This is an important result and highlights the disparities in age and is good pointer for anyone targeting to educate caregivers.

Employment status: the results from this study show a weak relationship between the knowledge level of the caregiver and their employment status. This was a surprising result given that it's envisaged that those employed would spend far less time compared to those who are not employed and thus were expected to be slightly knowledgeable.

Period living with the patient: the period with patient significantly related to the knowledge of the caregiver on schizophrenia. This result showed a strong positive relationship. This is expected because the length of time directly translates to the period of interacting and walking with the patient through the management of schizophrenia.

Relationship with the patient: Key to understanding how knowledgeable caregivers are and their attitude towards schizophrenia and its management lies in how the patients relate and link with the patient. This study shows that how patients relate to the caregivers did not significantly necessarily determine their knowledge and attitude towards 
schizophrenia. The weak relation between their knowledge of the caregiver did not depend on the relationship the caregiver had with the patient.

In summary, the length of time the caregiver has spent taking care of the patient and the age of the patient play a critical role in determining the knowledge of the caregiver on schizophrenia and its management. These key results underscore the importance of looking at individual factors and not broad factors that consider caregivers as a group. This concurs with the response from the key informant, that a caregiver whose patient has suffered a longer period with schizophrenia are more knowledgeable and have a favorable attitude.

\subsection{Relationship between the Caregivers' Factors on Their Knowledge and Attitude in Regards to Schizophrenia Cause and Management}

According to the nine key informants interviewed, there is still stigma towards mental illness, where most of the caregivers are more reluctant to be involved in the management. The most common type of admission non-voluntary admission brought by most relatives to the facilities due to acute psychosis or relapse of Schizophrenia.

Quantifying the key relationships highlighted above showed how the dependent variable changed with a unit change in the independent variable. Caregivers who have spent a considerably longer time (more than 5 years) with the patient were three times more likely to be more knowledgeable of schizophrenia and have a positive attitude compared to those caregivers who had spent less than 5 years with the patient. From this study, this was the most significant variable that determined the caregiver's knowledge of schizophrenia and their attitude towards the condition and management.

\section{Conclusions}

The caregivers of the Schizophrenic patients face many challenges such as financial constraints, emotional burnout and stigma from the public. Before the caregiver can be able to support the patient properly, they must first comprehend and accept that schizophrenia is a disorder of the brain just like diabetes is a disorder of the body. This shows that it is not anyone's fault and not an indication of moral or spiritual failure. Increased knowledge and insight, can help the caregivers to be able to cope with the condition in a more effective way, thereby improving prognosis.

\subsection{Knowledge of the Caregivers Regarding the Cause and Management Schizophrenia}

The most common source of information was from the experience of taking care of the patient and the information given by the health care workers at the facility. It's a great concern that many caregivers did not know the name of the diagnosis of their patient. This may limit the caregivers search for more information regarding the condition. A more knowledgeable caregiver is able to recognize the causes, symptoms of the condition and what aggravates the symptoms.
More than half of the respondents were familiar with the patient's medical history. This makes the caregiver able to support the patient-centered treatment promptly and also take care of themselves to avoid burnout. Since the patient is mentally incapacitated the psychiatrist rely on the caregivers to develop a patient centered treatment plan. This ensures continuity of care once the patient is stable and discharged from the health facility.

\subsection{Attitude of the Caregivers towards Schizophrenia Cause and Management}

The period the patient has lived with the patient, age of caregiver, relationship to the patient and the education level influence the attitude of the caregiver. Negative attitude of the caregivers acts an obstacle towards the recovery of the patient and the patient has a higher chance of relapse once discharged from the facility. The positive attitude of the caregivers will influence the quality of care they deliver to the schizophrenic patient. The caregivers perceived that the schizophrenic patient can be offered outpatient services without necessary being admitted. Most of the caregivers expressed that they accept the condition of the patient, they enjoy being around them and are able to take care of the patient once discharged.

\subsection{Factors That Influence the Knowledge and Attitude in Regards to Schizophrenia Cause and Management}

A caregiver can be either more knowledgeable or less knowledgeable and possess either positive or negative attitude. A more informed person tends to possess a positive attitude. The female caregivers were more knowledge compared to men since they were frequently visiting their relatives. The education level of the caregiver did not have significant impact on the knowledge regarding the condition. The factors which significantly influence one's knowledge and attitude regarding the condition is the caregiver's age, relationship with the patient and how long the person has lived with/ know the patient. An older caregiver has supported the patient for in a long period which makes them more knowledge and develop a favorable attitude. The length of period the caregiver has taken care of/ known the patient was the most significant variable to determine the knowledge and attitude of the caregiver.

\section{Recommendations}

Educational programs for the caregivers of patients will help to improve their capacity to be part of the patient support system. It's important to use multiple channels of passing information such as caregiver workshops, psycho education therapy, media, information education and communication (IEC) materials.

The results of this study emphasized that knowledge influence the attitude of the caregiver. Thus through improving the knowledge of the caregivers it will also facilitate a positive attitude.

The length the caregiver spends with the patient affects the 
knowledge and attitude, there is need to develop creative strategies to encourage the caregivers to interact with the patients frequently. Strategies such as phone call/ text reminder, invitation cards and caregiver fun days can be used.

\section{Suggestions for Further Research}

Further research should be carried out in the following areas:

1. A comparative study can be done among caregivers of Schizophrenia patients in different geographical settings.

2. A study needs to be conducted on pre and post psychosocial education assessment of the caregivers of Schizophrenic patients.

\section{References}

[1] Atwoli, D. L. (2014, October 5). No better time to address mental illness. Sunday Nation. Nairobi, Nairobi, Kenya: Sunday Nation.

[2] Awaritefe, E. (2005). Complementary attitudes to mental illness in Nigeria. Africa Journal of Psychiatry, 1, 37-43.

[3] Barbato, A. (1998). Schizophrenia and public health (1 ed.). Geneva: World Health Organization.

[4] Barry, P. (Ed.). (2002). Mental health and mental illness $\left(6^{\text {th }}\right.$ ed.). New York: Lippincott- Raven Publishers.

[5] Caqueo-Urízar, A. (2011). Attitudes and burden in relatives of patients with Schizophrenia in a middle income country. Coping with Schizophrenia. Retrieved from http://www.ncbi.nlm.nih.gov/pmc/articles/PMC3191329/.

[6] Coursey, A. (2001). Impact of an educational support group of family participants who take care of their schizophrenic relatives.. Journal of Consulting and Clinical Psychology, II (57), 232-236.

[7] Dickson, A. H. T. H. e. S. R. o. C. B. J. u. A.-F. R. i. W. R. u. A (2002). Attitudes about Schizophrenia from the pilot site of the WPA; worldwide campaign against the stigma of Schizophrenia. [Epidemoilogy journal]. Soc Psychiatry Psychiatr Epidemiology 37 (10), 475-482.

[8] Gabriele et al. (2007). Caregiver psychoeducation for Schizophrenia. American Psychiatic Association, 22 (7), 479-480.
[9] Gomez, W. (2003, 12th June, 2003). Shifting blame from ill relatives. Schizophrenia bulletin, 2, 574-581.

[10] Holmes et al. (1999). Changing Attitudes About Schizophrenia. Schizophrenia bulletin, 25 (3), 156-178.

[11] Kavanagh, D. (2007). Schizophrenia on overview and practical handbook. London: Chapman and Hull.

[12] Lieberman, J. (2004). Comprehensive care of Schizophrenia. A textbook of clinical management. New York: Martin Dunity limited.

[13] Lynnae et al. (2006). African-American Community Attitudes and Perceptions toward Schizophrenia and Medical Research: An Exploratory Study. Journal of the medical associatioc, 98 (1), 10 .

[14] Magaru, M. (2012). knowledge, attitudes and practices of caregivers of patients with Schizophrenia in port moresby, papua new guinea. Unpublished Academic, University of Papua New Guinea, Papua New Guinea, Papua New Guinea.

[15] Murray Robin, J. P., Cannon Mary. (2008). The epidemiology of Schizophrenia (Vol. II). New York: Cambridge University Press.

[16] Ndetei et al. (2009). Perceived economic and behavioural effects of the mentally ill on their relatives in Kenya: a case study of the Mathari Teaching and Referral Hospital. Africa Journal of Psychiatry, 12 (1), 293-299.

[17] Ngugi, A. M. (2011). Silenced minds; the systemic neglect of the Mental Health system in Kenya.

[18] Noreen, F. C. (Ed.). (2000). Psychosocial interventions for people with Schizophrenia ( ${ }^{\text {rd }}$ ed.). Hampshire: Palgrave Macmillan.

[19] Oginga, A. (2009). Respecting the rights and needs of mentally ill people living in Laikipia, Meru South, Nyeri, and Nyandarua Baseline. [Baseline study report]. Basic needs UK in Kenya rural program, 1 (1), 54-66.

[20] Otony, D. (2008). Psychiatric Nursing (1 ed. Vol. 1). Toronto: Thomson delmar learning publisher.

[21] Reine et al. (2004). Caregiver burden in relatives of persons with Schizophrenia: an overview of measure instruments]. Overview measurement of instruments. Retrieved from http://www.ncbi.nlm.nih.gov/pubmed/14567165

[22] Silvano, A. (2009). Interpretation of Schizophrenia London: Granada Publishing Limited. 